\title{
The light at the end of the tunnel: tunnel bleeding following per-oral endoscopic myotomy
}

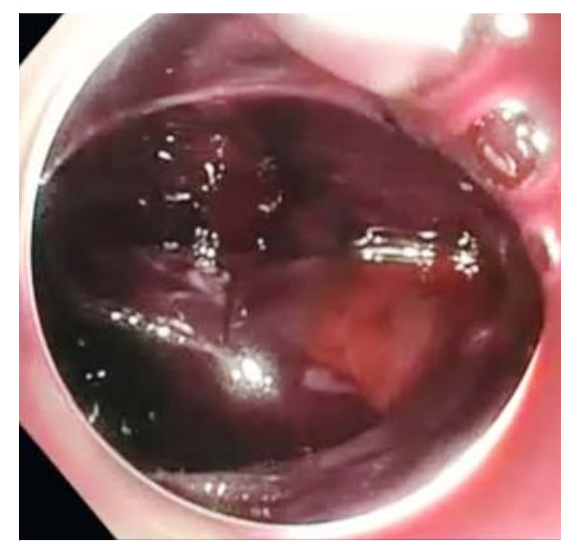

- Fig. 1 Large hematoma at the entrance of the tunnel.

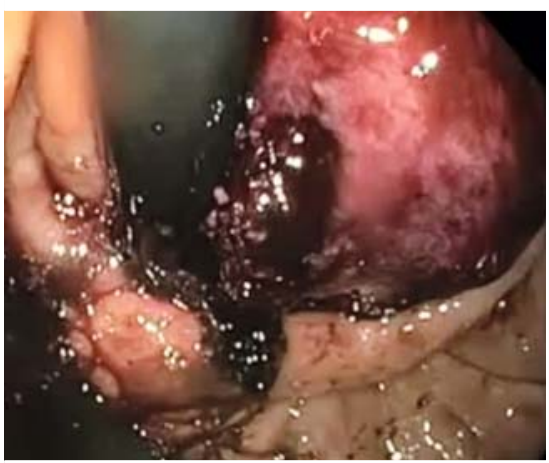

Fig. 2 Pressure ulcer caused by the hematoma at the esophagogastric junction.

Per-oral endoscopic myotomy (POEM) is a relatively safe procedure in expert hands. Complications associated with POEM include pneumoperitoneum, pneumothorax, and subcutaneous pneumothorax. Bleeding during the procedure can occur and is usually treated with the use of coagulation forceps. Delayed bleeding is rare, occurring in only $0.2-0.7 \%$ of patients [1, 2].

A 73-year-old woman with history of achalasia for 10 years and a history of Heller myotomy presented with recurrence and underwent per-oral endoscopic myotomy (POEM). A posterior POEM was
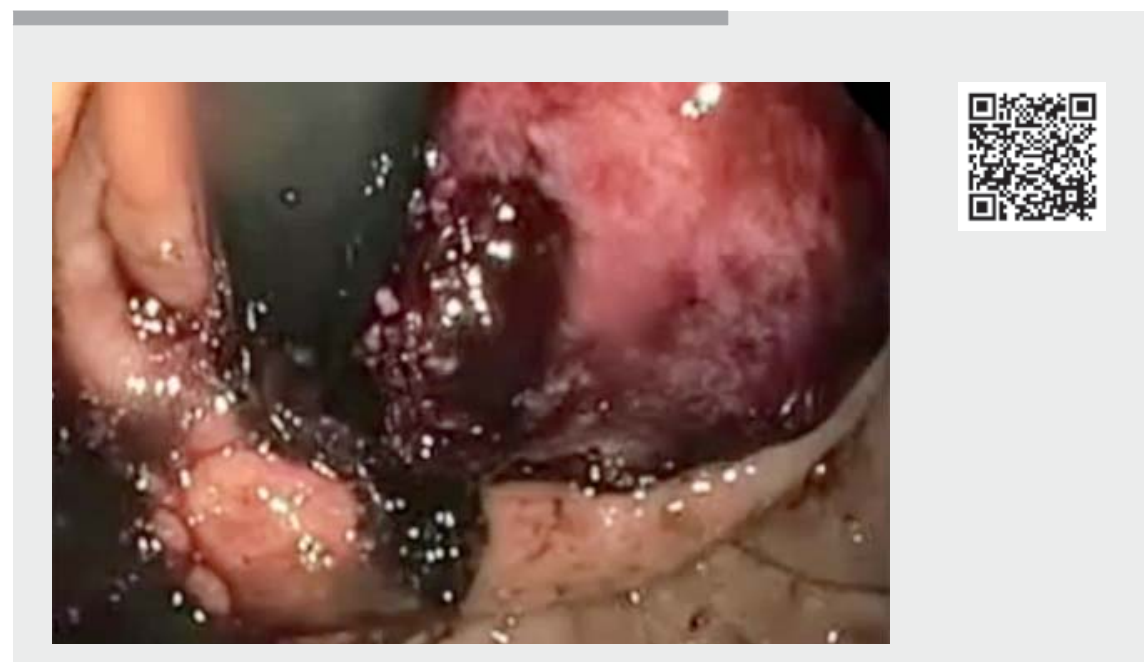

$\checkmark$ Video 1 Technique to control bleeding into a tunnel after a peroral endoscopic myotomy.

performed successfully without any complications. At 12 hours following the procedure, she developed hematemesis associated with significant hypotension. She was resuscitated and an emergent upper endoscopy was performed. Endoscopy revealed distension of the tunnel and a large clot below the gastroesophageal junction eroding into the stomach from the tunnel ( $\triangleright$ Fig.1). The tunnel was then opened by removing the hemostatic clips. The scope was advanced into the tunnel with an endoscopic cap (\Fig.2) (\Video 1). A snare was used to clean large clots from the tunnel. Coagulation forceps was used to coagulate any visible vessel. The tunnel was washed with gentamicin. The opening of the tunnel was then closed with hemostatic clips. The patient did well after the procedure and was discharged 24 hours later. At 1 month follow-up, patient reported resolution of her dysphagia and no further signs of bleeding. At 1-year follow-up, no dysphagia was reported by the patient.
Intraoperative bleeding during POEM is usually minimal but can occur during any of the steps of POEM. Bleeding during the procedure tends to be self-limiting and respond to coagulation.

Delayed bleeding can manifest in the first 48 to 72 hours after POEM. It is uncommon and is seen in $0.2 \%$ of patients [2]. Management entails re-entry into the tunnel, evacuating any blood clots, and identifying and coagulation of the bleeding site.

Endoscopy_UCTN_Code_CPL_1AH_2AC

Competing interests

Dr. Kahaleh is a consultant for Boston Scientific, Concordia Laboratories Inc, ABBvie, and MaunaKea Tech. He has received grant support from Boston Scientific, MaunaKea, Apollo Endosurgery, CookEndoscopy, ASPIRE Bariatrics, NinePoint Medical, Merit Medical, Olympus, and Interscope Med. 
Vicky Bhagat, Resheed Alkhiari, Michel Kahaleh ${ }^{\odot}$

Department of Gastroenterology, Robert Wood Johnson Medical Center, New Brunswick, New Jersey, United States

\section{Corresponding author}

\section{Michel Kahaleh, MD}

Department of Gastroenterology, Robert Wood Johnson University Hospital, 1 RWJ Place, MEB 464, New Brunswick, NJ 08901, United States

Fax: +1-732-235-7307

mkahaleh@gmail.com

\section{References}

[1] Li QL, Zhou PH, Yao LQ et al. Early diagnosis and management of delayed bleeding in the submucosal tunnel after peroral endoscopic myotomy for achalasia (with video). Gastrointest Endosc 2013; 78: 370-374

[2] Nabi Z, Reddy DN, Ramchandani M. Adverse events during and after per-oral endoscopic myotomy: prevention, diagnosis, and management. Gastrointest Endosc 2018; 87: 417

\section{Bibliography}

Endoscopy 2021; 53: E464-E465

DOI 10.1055/a-1346-7802

ISSN 0013-726X

published online 4.2.2021

(c) 2021. Thieme. All rights reserved.

Georg Thieme Verlag KG, Rüdigerstraße 14,

70469 Stuttgart, Germany

\section{ENDOSCOPY E-VIDEOS}

https:/|eref.thieme.de/e-videos

回回 Endoscopy E-Videos is a free 然故 access online section, reporting 回和: on interesting cases and new techniques in gastroenterological endoscopy. All papers include a high quality video and all contributions are freely accessible online.

This section has its own submission website at

https://mc.manuscriptcentral.com/e-videos 